\title{
Mirar envers el futur: evolució demogràfica i evolució de l'ús del valencià a Borriana
}

\author{
Modest Barrera Aymerich (modestbarrera@gmail.com) \\ JoAn R. MonfERrer DAUdí (joan.monferrer@uji.es) \\ Universitat Jaume I
}

\section{Evolució Demogràfica de Borriana (1986-2012)}

Resulta inherent als homes, i per extensió a la societat, evolucionar, sense que això signifique ritme constant, ni tan sols progrés, simplement transformació. És el que s'esdevé de les relacions econòmiques, cultural i polítiques que mantenen els homes, tot plegat relacions socials. I de la mà dels canvis, que sovint desdibuixen les estructures o fonaments, els reptes de solucionar els problemes que les alteracions produeixen. Uns reptes que sovint es plantegen com una manera de preservar, en la mesura que siga possible, les fórmules tradicionals de convivència, mentre que d'altra banda pretenen adreçar tot el potencial de les transformacions al desenvolupament. Difícils de quadrar, en qualsevol cas, aquestes dues tendències, la de preservar allò que considerem nostre i la necessitat de progressar, considerant la inevitabilitat de canviar i el desig d'estabilitat, d'equilibri, precisament per poder interactuar des de bases sòlides i així poder canviar.

Taula 1. Evolució de la població $i$ variacions anuals. Font: INE.

\begin{tabular}{|c|c|c|c|c|c|c|c|}
\hline \multirow{2}{*}{ Any } & \multirow{2}{*}{ Població } & \multicolumn{2}{|c|}{ Variacions } & \multirow{2}{*}{ Any } & \multirow{2}{*}{ Població } & \multicolumn{2}{c|}{ Variacions } \\
\cline { 6 - 8 } & & Absoluta & Any & & & Absoluta & \% \\
\hline 1986 & 25.178 & & & 1999 & 26.323 & 226 & 0,86 \\
\hline 1987 & 25.369 & 191 & 0,75 & 2000 & 26.499 & 176 & 0,66 \\
\hline 1988 & 25.725 & 356 & 1,38 & 2001 & 27.055 & 556 & 2,06 \\
\hline 1989 & 25.942 & 217 & 0,84 & 2002 & 27.794 & 739 & 2,66 \\
\hline 1990 & 26.067 & 125 & 0,48 & 2003 & 29.250 & 1.456 & 4,98 \\
\hline 1991 & 25.671 & -396 & $-1,54$ & 2004 & 30.059 & 809 & 2,69 \\
\hline 1992 & 25.856 & 185 & 0,72 & 2005 & 31.281 & 1.222 & 3,91 \\
\hline 1993 & 26.273 & 417 & 1,59 & 2006 & 32.349 & 1.068 & 3,30 \\
\hline 1994 & 26.404 & 131 & 0,50 & 2007 & 33.255 & 906 & 2,72 \\
\hline 1995 & 26.592 & 188 & 0,71 & 2008 & 34.235 & 980 & 2,86 \\
\hline 1996 & 26.211 & -381 & $-1,45$ & 2009 & 34.565 & 330 & 0,95 \\
\hline 1997 & & & & 2010 & 34.896 & 331 & 0,95 \\
\hline 1998 & 26.097 & -114 & $-0,44$ & 2011 & 35.433 & 537 & 1,52 \\
\hline & & & & 2012 & 35.598 & 165 & 0,46 \\
\hline
\end{tabular}

L'evolució demogràfica de Borriana durant els darrers anys reflecteix la magnitud dels canvis i, alhora, permet intuir els reptes que ha d'afrontar la societat. Sempre amb les 
dades del padró continu de l'Institut Nacional d'Estadística, en primer lloc recollides en la taula i gràfica número 1 , podem veure com en els darrers vint-i-cinc anys, els guanys demogràfics nets són superiors als deu mil veïns — gairebé un trenta per cent més-, una xifra que cal magnificar si considerem que els guanys més significatius es produïren entre 2001 i 2007.

Evidentment aquest increment tan significatiu, que correspon a una tendència general experimentada per tots els nuclis urbans — sobretot, si a més són costaners - (Gozálvez, 2004: 141-155), no és el fruit d'un creixement vegetatiu, bé perquè Borriana es troba immergida en allò que coneixem com a cicle demogràfic modern — amb taxes de natalitat baixes i envelliment de la població-, bé perquè això no podria explicar un canvi de tendència tan accentuat com el que s'observa entre finals del segle xx i començaments del XXI. Aquest canvi, tal i com passa per regla general en totes les àrees urbanes, és el resultat de fluxos immigratoris que tingueren Borriana com a destí atrets pel creixement econòmic verificat a partir del canvi de segle i lligat sobretot a sectors com la construcció i els serveis.

Gràfica 1. Evolució de la població de Borriana. Font: INE.

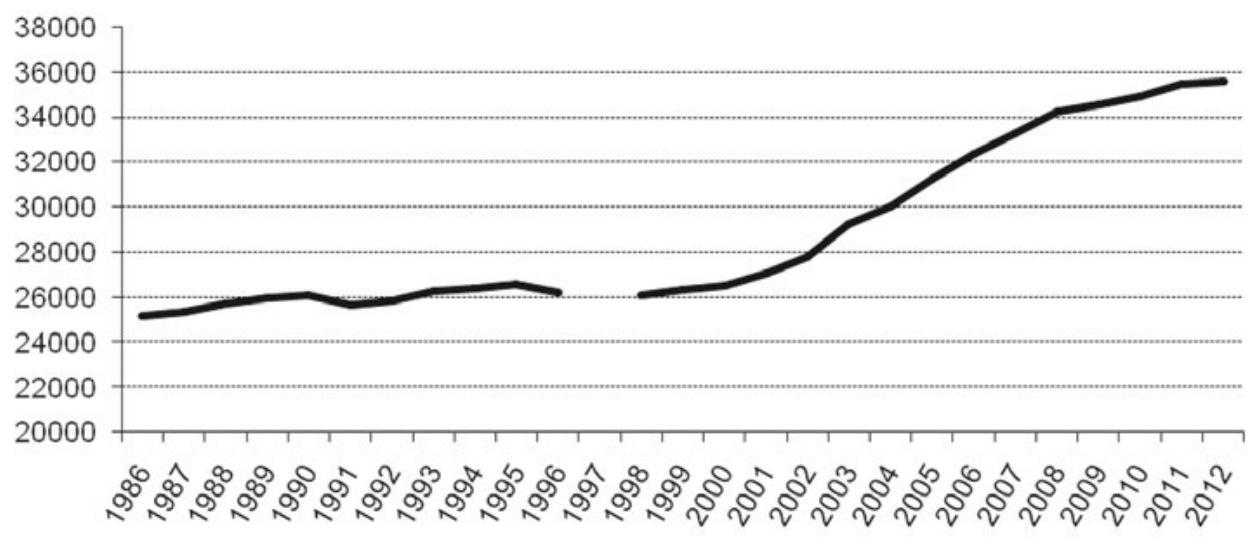

Si és cert que Borriana sempre ha crescut gràcies a les aportacions d'immigrants, que alhora rejovenien la població i provocaven repunts en la natalitat, el que n'ha canviat és l'origen. En efecte, encara en 1980 la major part dels immigrants provenien de territoris com Aragó, Andalusia i la Manxa, els quals podien arribar a representar gairebé un trenta per cent de la població (Castelló, 1988: 93-118). Els fluxos d'immigrants originaris d'altres indrets de l'Estat pràcticament s'aturaren en la dècada dels anys noranta, per la qual cosa el creixement va arribar a ser negatiu, considerant l'envelliment progressiu de la població. La tendència es va invertir, i a més de manera molt intensa, a començament de l'actual segle, però aquesta vegada no va ser l'èxode rural des de l'interior d'Espanya el responsable del creixement dels nuclis costaners (Guerrero, 2005), sinó que va ser la immigració estrangera fruit del creixement assolit durant els darrers anys que va augmentar la distància entre el desenvolupament del nostre país i alguns països propers geogràficament parlant o amb certa afinitat cultural. 
Taula 2. Població segons el lloc de naixement i edat a 1 de gener de 2012. Font: INE.

\begin{tabular}{|c|c|c|c|c|c|c|c|}
\hline & & Total & $\%$ & Homes & $\%$ & Dones & $\%$ \\
\hline \multirow{4}{*}{ Total } & Total & 35.598 & & 17.801 & 50,0 & 17.797 & 50,0 \\
\hline & Menys de 16 & 6.374 & 17,9 & 3.270 & 9,2 & 3.104 & 8,7 \\
\hline & Entre 16 i 64 & 23.717 & 66,6 & 12.253 & 34,4 & 11.464 & 32,2 \\
\hline & 65 anys i més & 5.507 & 15,5 & 2.278 & 6,4 & 3.229 & 9,1 \\
\hline \multirow{4}{*}{ Nascuts a Espanya } & Total & 28.300 & 79,5 & 13.829 & 38,8 & 14.471 & 40,7 \\
\hline & Menys de 16 & 4.857 & 13,6 & 2.488 & 7,0 & 2.369 & 6,7 \\
\hline & Entre 16 i 64 & 18.061 & 50,7 & 9.121 & 25,6 & 8.940 & 25,1 \\
\hline & 65 anys i més & 5.382 & 15,1 & 2.220 & 6,2 & 3.162 & 8,9 \\
\hline \multirow{4}{*}{$\begin{array}{l}\text { Nascuts fora } \\
\text { d'Espanya }\end{array}$} & Total & 7.298 & 20,5 & 3.972 & 11,2 & 3.326 & 9,3 \\
\hline & Menys de 16 & 1.517 & 4,3 & 782 & 2,2 & 735 & 2,1 \\
\hline & Entre 16 i 64 & 5.656 & 15,9 & 3.132 & 8,8 & 2.524 & 7,1 \\
\hline & 65 anys i més & 125 & 0,4 & 58 & 0,2 & 67 & 0,2 \\
\hline
\end{tabular}

El resultat, tal i com es pot apreciar en les taules número 2 i 3, no sols va ser un fort creixement demogràfic sinó també canvis en la composició de la població borrianenca. Canvis pel que fa a l'estructura, perquè la població immigrant foren joves que capgiraren la tendència, bé que lleugerament, a l'envelliment de la població, bé pel fet de ser-ho i també perquè començaren a tenir els primer fills. Canvis, en segon lloc, en la composició perquè es va passar en la dècada dels anys noranta de no haver-hi pràcticament estrangers a suposar el vint per cent de la població de Borriana.

Taula 3. Població segons el seu lloc de naixement a 1 de gener de 2012. Font: INE.

\begin{tabular}{|c|c|c|c|c|c|c|c|c|c|c|c|}
\hline & $\vec{\varrho}$ & 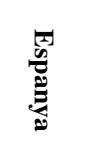 & $\%$ & 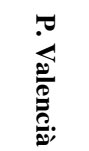 & $\%$ & 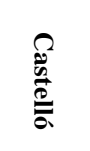 & $\%$ & 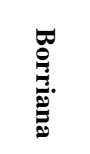 & $\%$ & 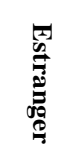 & $\%$ \\
\hline Borriana & 35.598 & 28.438 & 79,9 & 23.514 & 66,1 & 22.141 & 62,2 & 15.247 & 42,8 & 6.894 & 19,4 \\
\hline Hombres & 17.801 & 13.924 & 78,2 & 11.577 & 65,0 & 10.937 & 61,4 & 7.547 & 42,4 & 3.390 & 19,0 \\
\hline Dones & 17.797 & 14.514 & 81,6 & 11.937 & 67,1 & 11.204 & 63,0 & 7.700 & 43,3 & 3.504 & 19,7 \\
\hline
\end{tabular}

Els canvis en la composició per edat i sexe, que poden veure's en la gràfica número 2 , resulten aclaparadors. Així, ja es pot apreciar que les cohorts d'edat entre 10 i vint anys, les quals nasqueren en la darrera dècada del segle $\mathrm{xx}$, eren sensiblement inferiors en nombre a les precedents, i aquesta havia sigut la tendència pràcticament des de la dècada dels anys vuitanta. Per això és que en aquestes dècades pràcticament no hi havia creixement demogràfic, i fins i tot en alguns anys era negatiu. Tanmateix, de cop i volta es va invertir la tendència, i els immigrants que hi arribaren comptaven entre vint i quaranta anys, contribuint a corregir els desequilibris en la base i a atorgar-li un caràcter expansiu durant els darrers anys. 
Gràfica 2. Estructura demogràfica per edat i sexe a 1 de gener de 2012. Font: INE.

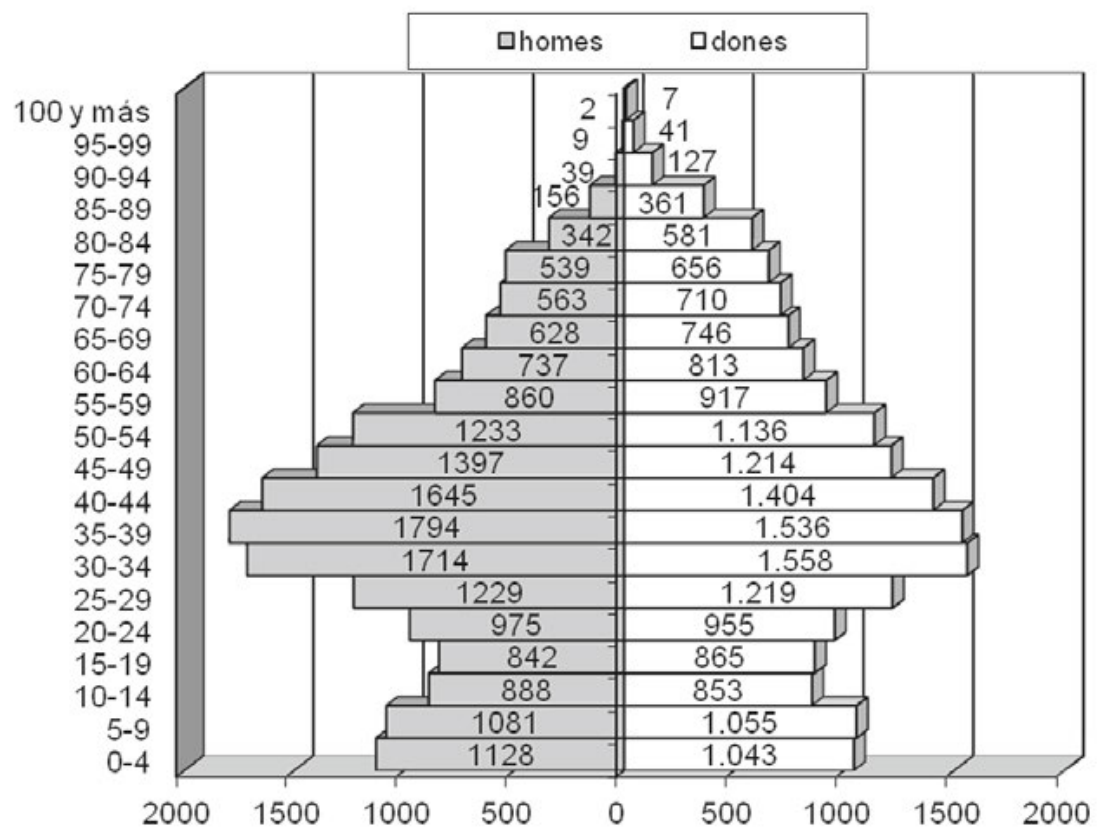

Un caràcter expansiu de la natalitat que, d'alguna manera, compensa encara el fet que el flux d'immigrants pràcticament haja desaparegut, per la qual cosa l'evolució demogràfica palesa signes d'estancament, que serien de recessió si no fóra per aquest efecte rejovenidor de la immigració.

Una població jove i estrangera, tant pel naixement com per l'origen, aquest és el canvi qualitatiu que cal afegir al quantitatiu, atreta tant per les possibilitats laborals que oferia la nostra societat com per la qualitat de vida que el nostre estat del benestar prometia. I quan el creixement s'ha esmorteï, i la tendència és a l'aturament, hi queda un canvi en la composició de la societat borrianenca.

Un canvi a afegir a altres que ja s'havien produït en dècades anteriors - ens referim a l'arribada d'immigrants d'altres indrets d'Espanya-, però que ara presenta una major diversitat geogràfica i, és clar, cultural. Això precisament és el que palesa la lectura de la taula número 4, on els percentatges s'han extret del total de cada continent de procedència. Els nostres veïns nascuts a l'estranger vingueren per proximitat geogràfica, serà el cas dels magribins - especialment els marroquins -, també per afinitat cultural com correspondria als iberoamericans, o per la combinació de tots dos aspectes com seria el cas dels residents originaris d'altres països de la Unió Europea, com ara la proximitat geogràfica -i a tot estirar la possibilitat de gaudir de bones comunicacions - i afinitat política derivada de l'adscripció a la Unió Europea. Acompanyant aquestes consideracions, ens referim al fet que l'arribada dels primers immigrants va tindre un efecte cridada sobre els seus paisans; només així podem explicar la gran concentració d'immigrants procedents de Marroc i, sobretot, de Romania a Borriana - per extensió també a tota la comarca. 
Taula 4. Origen dels estrangers de Borriana a 1 de gener de 2012. Font: INE.

\begin{tabular}{lrrrrrr}
\hline & Total & \% & Homes & \% & Dones & $\%$ \\
\hline Total & 35.598 & & 17.801 & & 17.797 & \\
\hline NASCUTS A L'ESTRANGER & 7.298 & 20,50 & 3.972 & 22,30 & 3.326 & 18,70 \\
\hline Total Europa & 4.460 & 61,10 & 2.349 & 59,10 & 2.111 & 63,50 \\
Unió Europea & 4.390 & 98,40 & 2.319 & 98,70 & 2.071 & 98,10 \\
Romania & 3.710 & 84,50 & 1.935 & 83,40 & 1.775 & 85,70 \\
Resta Unió Europea & 680 & 15,50 & 384 & 16,60 & 296 & 14,30 \\
Europa No Comunitària & 70 & 1,60 & 30 & 1,30 & 40 & 1,90 \\
\hline Total Àfrica & 2.294 & 31,40 & 1.373 & 34,60 & 921 & 27,70 \\
Algèria & 256 & 11,20 & 164 & & 92 & \\
Marroc & 1.893 & 82,50 & 1.109 & 80,80 & 784 & 85,10 \\
Nigèria & 73 & 3,20 & 45 & 3,30 & 28 & 3,00 \\
Resta Àfrica & 72 & 3,10 & 55 & 4,00 & 17 & 1,80 \\
\hline Iberoamèrica & 337 & 4,60 & 131 & 3,30 & 206 & 6,20 \\
Colòmbia & 146 & 43,30 & 66 & 50,40 & 80 & 38,80 \\
Resta Iberoamèrica & 191 & 56,70 & 65 & 49,60 & 126 & 61,20 \\
\hline Total Àsia & 159 & 2,20 & 106 & 2,70 & 53 & 1,60 \\
Xina & 66 & 41,50 & 033 & 31,10 & 33 & 62,30 \\
Pakistan & 75 & 47,20 & 60 & 56,60 & 15 & 28,30 \\
Resta Àsia & 18 & 11,30 & 13 & 12,30 & 5 & 9,40 \\
\hline Oceania i Apàtrides & 2 & 0,01 & 1 & 0,01 & 1 & 0,01 \\
\hline & & & & & &
\end{tabular}

Tot plegat un canvi en la composició social que, alhora, també ho és cultural. Pel que fa a la composició social, l'arribada de població adulta i jove, amb el consegüent repunt de la natalitat, planteja la necessitat de continuar amb els esforços en les àrees d'educació i sanitat, considerades aquestes uns vehicles fonamentals per a la integració i convivència (Piqueras, 2007: 353 i ss.). Aquests són, precisament, els gran reptes sobre els quals cal bastir el desenvolupament de Borriana.

\section{Evolució de l’Ús del Valencià a Borriana (1930-2014)}

\subsection{Introducció}

L'evolució de l'ús del valencià a Borriana s'ha mantingut de manera reeixida des de fa dècades, malgrat el procés de castellanització que es va produir principalment en la segona meitat del segle xx dins del procés general de castellanització que va patir el País Valencià des del segle XIX iniciat a la ciutat de València i, posteriorment, a la ciutat d'Alacant, que va incidir en la resta de ciutats valencianes progressivament segons el nombre d'habitants. D'altra banda, la immigració a Borriana del segle xx, especialment intensa en les dècades dels 60 i 70, va ser absorbida lingüísticament per dues raons fonamentalment en tractar-se d'immigració interior procedent principalment dels pobles muntanyencs de la província de Castelló (Alt Millars), de Terol i d'Andalusia: l'activitat econòmica principal a què es van incorporar era l'agricultura i la construcció, 
i la permeabilitat social va ser clau perquè es formaren noves famílies entre els fills dels immigrants i persones nascudes a Borriana, amb el valencià com a signe d'integració social. Mentrestant, la burgesia local anava abandonant la llengua pròpia en les relacions familiars i, sobretot, amb els fills, en benefici del castellà com a marca d'ascens social. Però les coses han canviat molt en el segle Xxi amb l'arribada d'un fort flux d'immigrants procedents majoritàriament de Romania i del Magrib.

En aquest apartat ens plantegem fer una anàlisi de la situació des de l'inici del procés de substitució lingüística, allà pels anys 30 del segle passat, fins als nostres dies, amb l'aportació de suggeriments per superar aquest procés de castellanització i redreçar la tendència en benefici d'un ús normalitzat del valencià.

\subsection{De 1930 a 1960}

L'inici de la castellanització a Borriana l'hem de situar a partir de la dècada dels 30 del segle xx, com en la major part de ciutats mitjanes del País Valencià. El que a València havia començat al segle XVIII amb l'alta burgesia i, sobretot, s'havia estès al segle XIX amb la burgesia mitjana, arriba a les ciutats mitjanes valencianes al segle xx i Borriana no n'és una excepció. Fins aleshores, a Borriana es podia viure plenament en valencià en tots els àmbits, tot i que l'administració i la justícia eren en castellà (la relació burocràtica del ciutadà amb l'administració i la justícia era mínima en comparació a l'actual), l'església feia les celebracions litúrgiques en llatí tret de l'homilia, que es feia en castellà, Borriana va pertànyer a la diòcesi de Tortosa fins als anys 60 i els capellans es relacionaven amb els feligresos en valencià, però el més important de tot és que els índexs d'escolarització eren baixíssims i de molt curta durada, fet pel qual el contacte amb el castellà de la majoria de borrianencs era poc significatiu.

En general, l'augment de la població a Borriana fins a la dècada dels 30 del segle passat, a causa del creixement vegetatiu i dels moviments migratoris, no va suposar cap retrocés en l'ús del valencià com a consequiència de la forta immersió lingüística a què va ser sotmesa la població nouvinguda per l'alt nivell d'ús del valencià en aquell temps. La qual cosa va provocar l'absorció progressiva, amb una certa rapidesa, com a resultat de la gran permeabilitat social que en va facilitar la barreja amb la població autòctona. Posteriorment, en les dècades dels 40 i 50, la població es mantindrà bastant estable, amb poca incidència pel que fa a la immigració.

En la postguerra, amb una economia de subsistència i dos grans successos climatològics que van marcar negativament l'economia local - la gran nevada i la gelada del $46 \mathrm{i}$ del 56 - , el model social no canvia substancialment respecte a la dècada anterior. Tot $\mathrm{i}$ que la castellanització es veu reforçada en l'esfera del poder — política, guàrdia civil, administració, església i escola - i en la burgesia local, com a resultat de la victòria del bàndol franquista. El castellà serà l'única llengua d'ús públic al llarg de tota la dictadura, el valencià quedarà relegat a l'àmbit familiar i, a poc a poc, anirà relegant-se d'aquest àmbit en les famílies acabalades del poble.

En aquests anys, dècades dels 40 i 50, es creen a Borriana dos col-legis privats de xics amb el suport de la burgesia local: els Frares (1938) i els Salesians (1940). Els de xiques encara tardarien: d'acord amb la manera de pensar de l'època, les xiques no calia que estudiaren. Pel que fa a les escoles públiques a Borriana, n’hi havia dos: les escoles 
velles, el Cervantes, i les escoles noves, el Viciana (sense oblidar les escoletes del port i de Santa Bàrbara), totes elles d'educació Primària. De Secundària o Batxillerat, no n'hi havia cap. Progressivament, augmenta el nombre d'estudiants a Borriana, si bé en aquests anys la principal opció és l'abandonament prematur de l'escolarització dels fills de les classes proletàries per dedicar-se a treballar i a ajudar a casa, cosa que no passa amb les classes burgeses (comerciants i terratinents). Alguns dels que abandonen l'escolarització per treballar acudeixen per les nits a acadèmies privades per completar la seua formació. És clar que l'única llengua vehicular de l'ensenyament és el castellà.

Així, el castellà es consolida com a llengua de cultura, tret d'alguna manifestació popular com les falles on es manté el valencià popular en les crítiques dels monuments. Com a fita significativa de la llengua escrita en l'àmbit de la cultura borrianenca trobem l'any 1956 l'aparició del Buris-ana: «els fundadors - de l'ABC, un grup de patricis borrianencs - van tindre la possibilitat de demostrar la seua vocació valencianista i a l'ensems europeista, amb iniciatives diverses com la publicació del butlletí Buris-ana» (<http://www.borriana.com/>). La llengua que predomina en la publicació és el castellà, fins als anys de la transició, tot i que apareixen algunes col·laboracions testimonials en valencià i en defensa del valencià.

En aquest context, les classes dominants opten pel castellà com a llengua de transmissió familiar; per tant, el que havia començat en els anys 30 en un grup reduït de famílies burgeses selectes es veu reforçat i ampliat progressivament en les dècades dels 40 i dels 50 , i posteriorment, fins que s'estableix i es generalitza en la burgesia alta i mitjana de Borriana: comerciants, terratinents, professionals liberals, funcionaris, personal administratiu. És el que coneixem com substitució lingüística per ascens social: els pares parlen en valencià entre ells i parlen castellà amb els fills. Pel que fa a la llengua escrita, el nombre de persones capaç de llegir-la era molt reduït, i d'escriure-la encara menys (tots autodidactes). Aquest era un dels motius pel qual les crítiques de les falles estaven escrites amb ortografia castellana i amb molta abundància de barbarismes i col-loquialismes.

\subsection{De 1960 a 1980}

La dècada dels 60 representa una època d'expansió econòmica i d'obertura del règim, cosa que significà per a Borriana l'arribada d'una generació important d'immigrants castellanoparlants procedents d'Andalusia principalment, però també d'altres indrets peninsulars. No era la primera vegada que arribaven immigrants, en els anys 30 ja n'havien arribat. En molts casos havien estat persones de l'interior de la província i d'alguns pobles de Terol, els anomenats popularment xurros, però aquesta vegada era diferent, eren persones que venien de molt més lluny i que havien protagonitzat uns moviments migratoris que van sacsejar la península. Les zones més riques de l'Estat, en procés d'expansió econòmica, van acollir milers de famílies de les zones rurals més deprimides, i a Borriana en van arribar una part. Es van concentrar bàsicament al barri de la Bosca i a la zona de la Vieta (als pisos de Florentina), però també en podíem trobar a les primeres finques construïdes a Borriana: al carrer Sant Domènec Savio o als pisos de Manuelet de Gómez, entre altres habitatges.

Aquesta immigració, a diferència del que va passar als cinturons industrials incipients de les grans ciutats del País Valencià, va ser integrada i absorbida a Borriana amb una 
certa facilitat, especialment pel que fa a la segona generació. Les raons fonamentals de la integració van ser el nombre d'immigrants, els sectors econòmics i laborals a què es van incorporar (bàsicament agricultura i construcció) $i$, sobretot, la permeabilitat social dels descendents, que en molts casos van formar noves famílies amb persones naturals de Borriana que tenien el valencià com a llengua pròpia.

Mentrestant, en l'àmbit de l'ensenyament, l'escolarització acabarà universalitzant-se fins als catorze anys i a començaments dels 60 es creen dos collegis privats per a xiques, Vil·la Fàtima (1959) i la Consolació (1965), que s'afigen als dos de xics que ja existien, i en l'ensenyament públic se'n crearan dos més, el Vilallonga (1964) i més tard l'Iturbi (1971). A finals dels 60 naix el primer institut d'ensenyament secundari a Borriana, el Jaume I (1969), i a finals dels 70 s'inaugurarà l'institut de formació professional Llombai. Al llarg d'aquestes dues dècades l'única llengua vehicular de l'ensenyament és el castellà, i el valencià és castigat i menyspreat per les institucions acadèmiques reforçant la idea que el castellà és una llengua de cultura, útil i necessària, i el valencià és una llengua inútil pròpia de les persones sense cultura.

En l'àmbit religiós, en els anys seixanta es produeixen dos fets cabdals per al procés de castellanització: el primer, la creació de la nova diòcesi Sogorb-Castelló (1960) i, el segon, la decisió del Concili Vaticà II (1962-65) d'introduir les llengües vulgars en la litúrgia. Pel que fa a la diòcesi, Borriana deixa de pertànyer a la diòcesi de Tortosa i passa a dependre de Sogorb; malgrat que els bisbes en aquestes dècades van ser catalans (Josep Pont i Gol, 1960-70, i Josep Maria Cases Deordal, 1972-96), el procés de castellanització de la diòcesi es veu reforçat, especialment amb el bisbe Cases Deordal. Però encara més important és la decisió del Concili Vaticà II (Sacrosanctum Concilium, cap. I, punt 36: Llengua litúrgica) d'introduir les llengües vulgars en la litúrgia, evidentment, a tot Espanya, a favor del castellà, ignorant completament el valencià. D’aquesta manera es consolida el castellà com a llengua oficial de l'església i els xiquets aprenen la doctrina en castellà i, a més a més, resen, es confessen i "parlen amb Déu" en castellà; el valencià no es propi tampoc per a les relacions espirituals i divines.

La burocratització de la societat augmenta a poc a poc i l'administració, les forces de seguretat i la justícia, així com la política - encara estem en ple règim franquista - no entenen cap altra llengua que no siga el castellà; per a ells parlar valencià és no ser ni sentir-se espanyol, i la por i la repressió ens duen a situacions ridícules i humiliants com ara el manteniment de converses en castellà de funcionaris amb persones del poble que s'expressen en castellà amb moltes dificultats.

La llengua de l'escola, de l'administració, dels mitjans de comunicació, de l'església i de la cultura, en definitiva la llengua del règim, és el castellà, que adquireix un gran prestigi en detriment de la llengua pròpia, el valencià. Aquest fet incideix de manera molt significativa en el procés de castellanització que ja s'havia iniciat molt abans, però que ara ho farà amb molta més força i determinació, i anirà baixant en l'escala social i afectarà no només a la burgesia més acabalada, sinó també a la mitjana i petita burgesia local. L'abandonament de la llengua pròpia per part dels parlants com a signe d'ascens social produeix situacions d'autoodi respecte a la llengua abandonada, el valencià, per tal de justificar la nova situació. Així, els nous castellanoparlants es converteixen en ferms defensors de la llengua i la cultura castellanes i mantenen actituds bel-ligerants amb els 
usos i amb els usuaris de la llengua abandonada, les persones que parlen valencià. Els nous castellanoparlants no poden admetre que una reunió d'una associació o col·lectiu es faça en valencià, que es parle en públic en valencià, que un escrit es faça en valencià, etc. "és una falta d'educació" - diuen encara ara.

\subsection{De 1980 a 2000}

Amb l'arribada de la democràcia, i després d'uns primers anys de transició convulsos $\mathrm{i}$ incerts, es consolida a tot l'estat espanyol un nou model polític i social basat en la descentralització; és l'aparició d'allò que alguns anomenaren l'Estat de les Autonomies - a tall d'exemple, recordem en aquest punt la gran manifestació a València del 9 d'octubre de 1977 sota el lema Ara, volem l'Estatut. L'estatut d'autonomia es va aprovar en 1982. En aquest context, els trets diferencials es consoliden com eixos centrals de les reivindicacions, i la llengua es converteix en el tret diferencial més significatiu que ens identifica, raó per la qual l'Estatut defineix el valencià com a «llengua pròpia de la Comunitat Valenciana» (art. 6) i, com a conseqüència, una de les primeres lleis que es va aprovar, després de l'Estatut, va ser la LUEV (Llei d'Ús i Ensenyament del Valencià, 1983).

El nou marc legislatiu i social va generar un context propici per redreçar les consciències d'un bon grup de borrianencs, quantitativament reduït però qualitativament molt rellevant, persones que pertanyien a la classe mitjana i amb formació universitària en la majoria de casos. Les coses començaven a canviar, ni que fóra de manera minsa. Cap a finals dels 80 s'inicia la primera línia d'ensenyament en valencià a Borriana, al col-legi públic Penyagolosa (que resultaria de la fusió de l'antic col-legi Cervantes i de l'efímer Hortolans). L'Agrupació Borrianenca de Cultura aplega una bona quantitat de socis en els primers anys de la transició com a refugi de les sensibilitats progressistes i valencianistes dels borrianencs de l'època, que anys més tard es traslladaran a les diferents opcions polítiques. En aquest context, no va ser una casualitat que en les eleccions municipals de 1983 el Partit Nacionalista del País Valencià obtingués una representació de dos regidors a l'Ajuntament de Borriana, un dels pocs municipis del País on va obtenir representació.

Un fet molt destacable per a l'ús i coneixement del valencià en la dècada dels 80 serà el nou mapa de mitjans de comunicació, especialment en el cas de la televisió. Si bé l'any 70 no arribava al 50\% el nombre de llars que disposava d'aparell de televisió, en els 80 es generalitza el seu ús i en la pràctica totalitat de llars es disposa d'un o més aparells. Fins als 80 només hi havia dues cadenes de televisió del grup RTVE, però a partir d'aquesta època s'enceta el meló de les concessions privades, amb tres cadenes noves (1990), i, sobretot, amb la creació dels canals autonòmics a Catalunya (1983) i a València (1989). TV3 arriba al País Valencià, primer a Sueca (1985) i després a la resta del País (1986), gràcies a les gestions d'Acció Cultural del País Valencià i a les aportacions econòmiques de molts valencians. A partir d'ara molts infants de Borriana creixeran amb el club Súper 3 , els dibuixos animats amb personatges que parlen com ells i les persones adultes que veuen i ouen en català sèries americanes, retransmissions esportives o les previsions del temps en què tant confiaven. Més tard, amb Canal 9, es multiplicarà l'audiència i el consum de programes en valencià. 
L'escola pública, encapçalada pel Penyagolosa i per l'èxit de la seua línia en valencià, introdueix progressivament les línies d'ensenyament en valencià de manera generalitzada en la dècada dels 90 i principis dels 2000, no sense els entrebancs característics dels detractors. En aquesta època les línies en valencià (Programa d'Ensenyament en Valencià, PEV) conviuen amb les línies en castellà (Programa d'Incorporació Progressiva, PIP). En el PEV la llengua curricular base és el valencià, el castellà s'imparteix com a assignatura, i a partir de 3r de Primària s'usa el castellà com a llengua vehicular en l'assignatura de Coneixement del Medi; en el PIP l'alumnat té el valencià com a assignatura i a partir de $3 r$ tenen l'assignatura de Coneixement del Medi en valencià, mentre que la resta d'assignatures s'imparteixen en castellà. Les escoles privades, per la seua banda, mantenen l'ensenyament en castellà amb el valencià com a assignatura. Posteriorment, per imperatiu legal, hauran d'implantar el Programa d'Incorporació Progressiva, però en els col·legis privats de Borriana no s'implanta cap línia en valencià. No és cap casualitat com tampoc no ho és el cas de l'església, que després d'un intent èpic i efímer de fer missa en valencià als Salesians (1977) per part del pare Vicent Martí († 2014), natural d’Alboraia, la resta de capellans van continuar fent la missa en castellà i l'església ha seguit utilitzant el castellà a Borriana com a llengua de la litúrgia, la catequesis i en totes les celebracions i relacions formals amb els feligresos, majoritàriament valencianoparlants. L'església valenciana no ha parlat valencià des de fa segles, alineant-se amb les tesis centralistes $\mathrm{i}$ castellanitzadores de la decimonònica burgesia dominant valenciana, que defensa la llengua com instrument folklòric que identifica les classes baixes i rurals del País, però que en cap cas serà identificada com element de modernitat, de progrés, de cultura i de ciència.

Com hem vist en les taules estadístiques de la part de demografia d'aquest capítol, les dècades dels 80 i 90 es caracteritzen per l'estabilitat demogràfica. Borriana es manté al voltant dels 25.000 habitants i aquesta estabilitat permet que el procés d'integració dels immigrants arribats en dècades anteriors es consolide.

Taula 5. Evolució del coneixement del valencià a la ciutat de Borriana (Montoya, 2011: 241)

\begin{tabular}{|c|c|c|c|c|}
\hline Any & Entén & Parla & Llig & Escriu \\
\hline 1986 & $96,6 \%$ & $76,8 \%$ & $32,3 \%$ & $9,6 \%$ \\
\hline 1991 & $97,5 \%$ & $79 \%$ & $60,0 \%$ & $26,2 \%$ \\
\hline 2001 & $95,3 \%$ & $72,7 \%$ & $64,8 \%$ & $33,4 \%$ \\
\hline
\end{tabular}

Així les coses, i analitzant les dades de la taula 5, podem afirmar que en les dècades dels 80 i 90 les destreses de comprensió i expressió orals es mantenen estables en els nivells de dècades anteriors, tot i que baixen una mica a causa de la incorporació de la població nouvinguda, però les destreses de comprensió i d'expressió escrites augmenten significativament: es duplica la comprensió escrita i quasi es quadruplica l'expressió escrita. Certament, l'escola ha estat el factor decisiu en aquesta empenta normalitzadora. Ara els valencianoparlants tenen una competència lingüística molt superior a la que hi havia en altres èpoques, però això no garanteix un major ús del valencià. Malgrat tot, en aquesta època s'aconsegueix una fita molt important: frenar la forta davallada de l'ús del valencià que s'havia iniciat en els anys $30 \mathrm{i}$ en la postguerra, i que s'havia incrementat exponencialment en les dècades dels 60 i 70. 


\subsection{El segle XXI}

La situació al segle Xxi ha estat ben diferent. L'estabilitat demogràfica del darrer quart del segle xx ha patit un trasbals en la primera dècada del segle XXI, amb un augment de més de 9.000 persones des de l'any 2000 - moltes persones en un període de temps molt breude les quals més de 7.000 (20\% de la població) són de procedència estrangera, bàsicament de dues comunitats: romanesos (3.710) i magribins (2.149), amb característiques culturals, lingüístiques i de relació social ben diferenciades. Fins ara, la població nouvinguda a Borriana havia estat quasi exclusivament castellana. A partir d'aquest moment, la barreja de llengües serà molt més complexa: llengües ambientals, llengües oficials, llengües de relació internacional. En una situació com aquesta la llengua que té totes les de perdre pel que fa a l'ús és la llengua minoritzada, en el nostre cas el valencià. Ara per ara, els colllectius d'immigrants es comporten de manera molt diferent i la integració social s'espera que siga també diferent. Per un costat, els romanesos, amb una llengua i una cultura romàniques, sembla que s'integren més fàcilment; per l'altre, els magribins, amb una llengua, una cultura i una religió més allunyades, sembla que s'integren amb més dificultats. Però el nostre interès, en relació a la integració i l'ús del valencià, s'ha de centrar especialment en les segones generacions, en les filles i els fills dels immigrants, en els borrianencs del futur. Què ha fet la societat borrianenca per facilitar-ne la integració?

L'escolarització obligatòria a l'estat espanyol fins als 16 anys fa que l'escola siga l'eina bàsica de socialització de tota la població, autòctona i immigrant. Però, com tots sabem, l'escolarització dels immigrants a Borriana, com al País Valencià, s'ha fet exclusivament a l'escola pública a causa de les polítiques conservadores que s'han dut a terme al llarg d'aquest període. La qual cosa, des del punt de vista lingüístic, ha suposat que majoritàriament l'escolarització s'haja fet en el programa d'ensenyament en valencià - el que socialment no ha estat una decisió positiva pel que fa a la integració, ja que no hi ha hagut una distribució equilibrada de l'alumnat immigrant entre els collegis públics i privats (concertats) per tal de facilitar-ne la integració social; lingüísticament, almenys, ha augmentat la competència lingüística en valencià d'aquest colllectiu. Mentrestant, les escoles privades, amb alumnat autòcton, han seguit emprant el programa d'incorporació progressiva, amb el castellà com a llengua base de l'ensenyament, incidint encara més en la castellanització de les classes mitjanes, tot i que la competència en valencià és superior ara a la de fa vint-i-cinc anys. En aquest període s'han creat dos col-legis públics nous per tal d'absorbir la forta demanda provocada pel ràpid creixement demogràfic: Novenes i Cardenal Tarancon. El primer, després d'un bon grapat d'anys en barracons, ja compta amb instal-lacions noves; però, el segon, encara perdura en barracons amb una minva creixent de sol-licituds d'ingrés que podria comportar la desaparició del centre. Una gestió nefasta de l'administració educativa, però coherent amb la seua estratègia ideològica, que s'estima més concertar amb la privada que potenciar l'escola pública i en valencià.

Pel que fa als mitjans de comunicació en valencià, en la dècada dels 2000 va seguir incrementant-se la seua presència qualitativament; els més menuts i els més grans n'eren els màxims consumidors. Però, darrerament, s'han succeït una sèrie d'esdeveniments que semblen "premeditats" perquè els valencians no tinguem accés a la informació en la nostra llengua: tancament de TV3 (17-02-2011), tancament de Ràdio 9 (28-11-2013), 
tancament de Canal 9 (29-11-2013), tancament de Catalunya Ràdio (21-01-2014). Com a conseqüència d'aquestes decisions del govern conservador de la Generalitat Valenciana, els valencians no rebrem cap informació en la nostra llengua ni des de la perspectiva valenciana i "quan ploga a tot Espanya nosaltres veurem 'lluir un sol que bada penyes". Dit d'una altra manera, els nostres xiquets no tindran programes infantils en valencià i els nostres majors hauran d'escoltar en castellà els pocs minuts que des de les cadenes estatals parlaran de les nostres coses, sense oblidar-nos dels esports, els informatius, l'oratge, el medi ambient, les festes, les tradicions, etc. Sobta - o no- que amb la gran quantitat de cadenes que emeten de forma il/legal, fins i tot algunes amb continguts il/legals en horari infantil, el Govern valencià haja actuat exclusivament contra les emissores que emetien en valencià. Certament, el poc temps que els mitjans de comunicació en valencià han emès, han fet una tasca normalitzadora importantíssima, lingüísticament i culturalment, malgrat la manipulació informativa a què han estat sotmesos. D'ara endavant l'única opció possible serà viure en castellà, gràcies a aquells valencians que mai no han volgut viure en valencià.

Amb el context cultural i lingüístic actual, l'administració autonòmica segueix utilitzant preferentment el castellà i l'administració local, si bé verbalment usa el valencià, en les relacions per escrit utilitza preferentment el castellà, tot i que els polítics locals usen majoritàriament el valencià, llevat d'alguna excepció rellevant. La premsa és exclusivament en castellà, tret d'algun cas que no passa de ser anecdòtic, i si excloem la revista degana local, el Buris-ana. El comerç local utilitza el valencià en els eslògans de les seues campanyes, però tota la informació i, en molts casos, el tracte amb els clients és en castellà. L'església segueix usant el castellà com a llengua vehicular de les seues celebracions i totes aquelles agrupacions que s'organitzen al voltant de l'església (confraries, passos de setmana santa, camí neocatecumenal, col·lectius festers, etc.) usen el castellà com a única llengua vehicular, tant en els actes com en els textos escrits, fins al punt que en el pregó de la Setmana Santa, amb la participació de lletraferits locals que escriuen habitualment en valencià, sempre es fa en castellà, com si les persones que assisteixen a aquests actes no foren del poble ni entengueren perfectament el valencià. Efectivament, no és un problema de competència lingüística en valencià, és un signe evident de l'abandonament de la llengua pròpia, d'allò que en sociolingüística s’anomena procés de substitució lingüística.

Un cas remarcable, pel que fa a l'ús i la normalització del valencià, és el de les falles. En el procés de substitució lingüística, en un acte d'hipocresia o de mala consciència, els grups socials que abandonen la llengua minoritzada dediquen un dia a l'any per a lloar-la, enaltir-la i per a pregonar les seues excel-lències; la resta de l'any usen la llengua dominant. Això era el que feien els poetes de la Renaixença com Teodor Llorente a finals del segle XIX i a principis del segle Xx a València i a Barcelona, a través dels jocs florals. La festa de les falles, d'alguna manera, ha estat l'hereva d'aquesta tradició per la seua condició de tradicional, valenciana i representativa "de l'essència del poble", i aquells jocs florals són ara les proclamacions, les pleitesies i tots aquells actes en què els lletraferits locals mostren les seues habilitats literàries en la llengua del poble, on el gènere que predomina és la poesia de tipus pairal o jocfloralesc. Així, el valencià és la llengua de les falles, les falles s'escriuen en valencià, els llibrets de falla també i les persones que s'incorporen a les comissions accepten el valencià com a llengua de relació entre els seus membres. A més a més, a partir 
dels anys 80 s'ha incorporat al món de les falles un grup important de persones amb una bona competència lingüística en valencià que ha dignificat l'ús normativitzat del valencià escrit en les falles i la qualitat literària dels llibrets i dels actes fallers, però sobretot ha fet que la festa de les falles siga un element de promoció i ús del valencià.

Tot i amb això, en aquests anys ens trobem davant d'una situació complexa que cal analitzar bé per eixir-nos-en amb èxit si volem que el valencià continue sent la llengua dels nostres fills, com ho fou dels nostres pares. La testimonial política lingüística feta des de l'administració autonòmica, si bé ha tingut algunes conseqüències positives en l'ensenyament, no ha estat capaç de frenar el procés de castellanització general de la societat valenciana i, a més a més, en l'actualitat, està patint un procés de retracció més que evident amb les decisions polítiques dels darrers anys. Els exemples més clars són el fracàs del Manifest d'Ares del Maestrat (2003) que regula l'ús del valencià en l'administració, impulsat per l'exconseller de Cultura González Pons, els darrers enfrontaments del president de la Generalitat amb l'Acadèmia Valenciana de la Llengua (AVL) o la supressió de línies en valencià de la consellera Catalá, sense oblidar el tancament dels mitjans de comunicació en valencià per decisió del Consell de la Generalitat, tot encobert sempre sota un enganyós discurs neoliberal que prima per damunt de tot una qüestionable i demagògica rendibilitat econòmica.

\subsection{Reflexions finals}

L'ús del valencià a Borriana, i també al País Valencià, depèn de dos factors: la integració lingüística i social de les persones immigrants i, sobretot, del fet que els valencianoparlants no abandonem l'ús del valencià. La integració dels col·lectius d'immigrants és un repte important que tenim per endavant, ja que aquesta integració pot beneficiar l'ús o l'abandonament del valencià, tot i que això no depèn dels immigrants, sinó dels valencianoparlants habituals que acaben parlant castellà en detriment del valencià com a llengua minoritzada per la influència dels prejudicis lingüístics propis de la visió burgesa dels setcentistes il·lustrats francesos que proclamaven: un estat, una llengua. El valencià no és ni millor ni pitjor que cap altra llengua; la diferència amb el castellà i amb la resta de llengües és que el valencià és la "nostra" llengua i no tenim cap motiu per a menysprear-la o rebutjar-la, ni per permetre que ens la malmeten, i menys encara quan nosaltres som a casa nostra i són els altres els qui hi vénen. Si no respectem i fem respectar allò que és nostre ningú ens ho respectarà. En una societat globalitzada com l'actual, les llengües minoritàries i minoritzades com la nostra estan abocades a l'extinció si no es fa res per protegir-les, i això no tan sols depèn de les polítiques lingüístiques impulsades per l'administració, sinó sobretot de les actituds dels parlants d'aquestes llengües.

Certament, la burgesia valenciana fa molt de temps que es va castellanitzar i que prefereix ser castellana, de manera excloent, a ser valenciana, i només es recorden del valencià com a eina folklòrica i jocfloralesca que recorda un passat propi però que és rebutjat com a eina de futur i de progrés. El valencià tan sols s'usa per a l'enfrontament entre valencians i per interessos electoralistes; és molt significatiu el fet que dels cinc presidents de la Generalitat Valenciana tres no parlaren mai en valencià, ni tingueren la voluntat de fer-ho (Eduardo Zaplana, de Cartagena, José Luís Olivas, de Conca, i l'actual, 
Alberto Fabra, de Castelló: vegeu <www.youtube.com/watch?v=bZPjiOWSfhc>) i, malgrat això, han estat capaços de convèncer l'electorat que ells eren els que millor defensaven els interessos i les senyes d'identitat dels valencians, sense oblidar la consellera del ram, María José Catalá, que en un acte polític de proclamacions de candidats a alcalde valencians del seu partit (01-03-2011) va demanar disculpes «por si me paso al valenciano, porque tengo ese "defecto"», després que l'exalcalde de Vila-real, Juan José Rubert, fóra escridassat en el mateix acte per parlar en valencià i, com a consequiència se'n passara al castellà: «hablo en castellano, como queráis, "perfecto"» (vegeu <www.youtube.com/watch?v=iWfo8qeW_ $\mathrm{xE}>$ ). Aquests són alguns exemples actuals de la realitat valenciana i del valencià, més enllà dels discursos i les paraules buides dels nostres dirigents, un reflex d'una situació en què la dignitat dels valencians es veu menyspreada, especialment entre els mateixos valencians.

Aquests fets es veuen reforçats quotidianament per altres que pateixen els valencianoparlants en l'àmbit personal i en la seua vida diària, malgrat el que diu la Constitució espanyola (art. 3) i l'Estatut d'Autonomia (art. 6). Així, algunes notícies recents sobre actituds de les forces de seguretat de l'Estat amb persones d'ací, que parlaven valencià exercint un dret constitucional, demostren que la normalització del valencià encara està molt lluny i que la pluralitat lingüística de l'Estat és una fal-làcia. No es pot admetre que el grau d'espanyolitat dels individus estiga en relació amb l'ús d'una llengua o d'una altra; si això és així no hem entès què vol dir que Espanya siga un estat plurinacional i plurilingüístic, o és que el nacionalisme espanyol és un nacionalisme excloent. Però el que més ens ha de preocupar als valencianoparlants és que aquestes actituds les defensen persones d'ací que han abandonat el valencià i que mantenen actituds bel-ligerants o de menyspreu (autoodi) contra les persones que utilitzen el valencià en les seues relacions públiques i privades, i situacions d'aquest tipus ens en trobem cada dia en tots els àmbits.

Finalment, voldríem acabar donant un missatge positiu sobre l'ús del valencià fent referència al que diu la cançó del grup valencià Al Tall (el Tio Canya) que «ja compta amb besnéts molt joves que alegren la seua cara». Malgrat tots els entrebancs que suposa la substitució lingüística del valencià pel castellà, el valencià a Borriana encara està molt viu i se sent com a llengua pròpia dels borrianencs, de la seua història i de la seua cultura; és una senya d'identitat pròpia que ens identifica com a borrianencs, i així ho veuen encara moltes persones que s'incorporen al nostre poble com a nous borrianencs des d'altres cultures. Si hem estat capaços de frenar el procés de castellanització, també serem capaços de redreçar la tendència i canviar-la amb una recuperació digna del valencià. El nostre treball de recuperació s'ha de centrar en les generacions més joves amb la utilització del valencià com a llengua de relació familiar, com a llengua vehicular de l'ensenyament i com a llengua de relació social, atorgant-li el prestigi social que es mereix i no permetent humiliacions públiques per usar la llengua dels nostres avantpassats; en definitiva, ser i sentir-nos borrianencs, sense menysprear la llengua dels altres. El nivell de competència lingüística global en valencià dels joves borrianencs no ha estat mai en els alts nivells actuals, i són ells els qui han de garantir el futur de l'ús del valencià. Avui no és estrany veure xiquets romanesos, magribins, subsaharians o xinesos jugant en valencià amb xiquets nascuts ací i això és molt positiu. Ara el que cal és crear la necessitat social de conèixer i usar el valencià entre els adults i els majors per normalitzar-ne l'ús i que no siga una anècdota que et parlen en valencià el metge o l'especialista, l'advocat, el jutge, el 
notari, el mestre, el capellà, el bisbe, els polítics, el botiguer i totes aquelles persones que acostumaven a parlar-te en castellà.

\section{BIBLIOGRAFIA}

Acadèmia Valenciana de la Llengua (2005): Llibre blanc de l'ús del valencià-I, València, Acadèmia Valenciana de la Llengua.

Castelló Traver, J.E. i altres (1988): Crecimiento y Crisis en la Población Valenciana, València, Publicaciones de la Generalitat Valenciana.

Conselleria de Cultura, Educació i Esport (2004): Coneixement i ús del valencià (CD-Rom), València, Generalitat Valenciana.

Conselleria D'Educació, Cultura i EsPort (2010): Coneixement $i$ ús del valencià, València, Generalitat Valenciana (<www.cece.gva.es/polin/docs/sies_docs/encuesta2010/index.html>).

GozÁlvez Pérez, V. (2004): «Evolución de la población valenciana durante la època migratoria (18571960), dins Historia, clima y paisaje. Estudios geográficos en memoria del profesor Antonio López Gómez, València, Universitat de València, 141-155.

Guerrero CAROT, F.J. (2005): El Palancia: nacer y emigrar. La evolución de la población (siglos XVI al $X I X)$, Castelló, Publicacions de la Universitat Jaume I.

Montoya, B. i A. Mas (2011): La transmissió familiar del valencià, València, Acadèmia Valenciana de la Llengua.

Ninyoles, R.L. (1985): Conflicte lingüístic valencià, València, Tres i Quatre.

Piqueras Infante, A. (2007): Capital, migraciones e identidades. Inmigración y sociedad en el País Valenciano: el caso de Castellón, Castelló, Publicacions de la Universitat Jaume I .

RuIz, F. i altres (2001): Diccionari de sociolingüística, Barcelona, Enciclopèdia Catalana.

\section{BIONOTES}

\section{Modest Barrera Aymerich}

(Borriana, 1962) Doctor en Història, professor. Ha publicat nombrosos treballs d'Història Moderna i Contemporània centrant-se en temes com la cultura i les mentalitats, la demografia i les institucions.

\section{Joan Ramon Monferrer Daudí}

(Borriana, 1962) Filòleg i professor de Didàctica de la Llengua a la Universitat Jaume I i professor de l'Escola Oficial d'Idiomes de Castelló. En el camp de la sociolingüística ha participat en diferents treballs de recerca per a l'associació Escola Valenciana i ha estat investigador extern del projecte $L a$ inseguridad lingüística de la lengua minorizada en el sistema educativo valenciano: análisis i propuestas de mejora (HUM2006-10229), finançat pel Ministeri d'Educació. La seua tasca investigadora principal se centra en l'ensenyament i aprenentatge de llengües, és coautor del Portfolio Europeu de les Llengües en format electrònic (ePel) del Ministeri d'Educació i ha participat en diversos grups de treballs per al disseny de nous currículums de les EOI i en el disseny de les proves actuals de la Junta Qualificadora de Coneixements del Valencià. 